\title{
DA SIMPLES ARQUIVÍSTICA À MODERNIDADE DIGITAL
}

\section{FROM THE ORDINARY FILING TO THE DIGITAL ERA}

\section{Luiza Wioppiold Vitalis}

Bacharel em Secretariado Executivo - Universidade de Santa Cruz do Sul UNISC

luizaw@unisc.br

\section{Liane Dannenberg Geötzke}

Bacharel em Automação de Escritórios e Secretariado - Universidade de Santa Cruz do Sul - UNISC

lianeg@unisc.br

\section{Leonardo José Andriolo}

Mestre em Administração pela Universidade Federal do Rio Grande do Sul UFRGS

landriol@unisc.br 


\section{RESUMO}

Neste trabalho se propõe estudar a trajetória da arquivística dentro da profissão de secretariado, abordando desde as primeiras formas de arquivamento até as formas de arquivamento eletrônico. Para este estudo, os principais embasamentos teóricos utilizados foram as obras: Arquivo: teoria e prática, de Paes (2002), Secretariado: do escriba ao web writer, de Sabino e Rocha (2004), e Paula (1995), Como elaborar a tabela de temporalidade documental: racionalização de custos de armazenagem e administração de arquivos empresariais, que expõem, além das técnicas básicas de arquivamento, as novas e modernas técnicas a serviço dos arquivos. O estudo pode ser classificado como exploratório, sendo que o levantamento dos dados foi realizado a partir da pesquisa bibliográfica. Dos resultados encontrados, destacou-se que um arquivo bem organizado oferece agilidade e praticidade ao profissional de secretariado condições importantes para o suporte às tomadas de decisão - a melhoria do espaço físico de um escritório, através da destinação dos documentos gerados, também é de fundamental relevância. Com a Tabela de Temporalidade Documental posta em prática, é possível implantar o Gerenciamento Eletrônico de Documentos e melhorar constantemente o processo de arquivamento.

Palavras-chave: Arquivo; Técnicas de Arquivamento; Arquivamento Eletrônico de Documentos. 


\section{ABSTRACT}

This article proposes to study the path of the archive science in the secretarial profession, making reference since the first ways to archive until the electronic ways of archiving. The main theory references used for this study were the books "Arquivo: teoria e prática", from Paes (2002), "Secretariado: do escriba ao web writer", from Sabino and Rocha (2004), and Paula (1995), "Como elaborar a tabela de temporalidade documental: racionalização de custos de armazenagem e administração de arquivos empresariais", that show, beyond the basic archiving techniques, the new and modern techniques at the archives service. This study can be classified as exploratory, due to the bibliographic source of this research. From the results found, it was highlighted that a well organized archive offers agility and practicality to the secretarial professional - important conditions to support the decision process - the improvement of the layout of an office through the destination of the documents produced, is also basically relevant. With the Documents Temporality Table put on practice, it is possible to implement the Electronic Documents Management and constantly improve the archiving proccess.

Key-words: Archive; Archiving Techniques; Electronic Documents Archiving. 


\section{INTRODUÇÃO}

Uma temática pouco discutida, e que só é lembrada ao se abrir um arquivo, é o método utilizado para organizar e dispor os documentos. As várias técnicas existentes só são válidas e aplicáveis se as pessoas que necessitam buscar determinada informação conseguirem localizar o documento que estão à procura, ou que Ihes seja solicitado, com agilidade e rapidez.

Atualmente, com as inúmeras tecnologias disponíveis e a facilidade de reprodução de dados, cresce dia a dia o número de documentos produzidos e recebidos pelas instituições, exigindo delas, cada vez mais, uma política de manutenção de seu acervo documental.

O profissional de secretariado executivo é responsável por essa manutenção dentro das empresas. Além de outras responsabilidades, cabe ao secretário(a), segundo Dudziak (2010), gerenciar informações e serviços, organizar as atividades administrativas, manter a agenda e os contatos, assessorar, orientar as ações cotidianas e cuidar da custódia, organização e gestão de documentos e arquivos.

Paes (2002) destaca que assim como a humanidade vem evoluindo técnica, científica e culturalmente através dos séculos, também o conceito de arquivo sofre modificações para atender aos desafios de um mundo em mudanças. Não apenas os conceitos, mas principalmente as técnicas de arquivamento.

As importantes mudanças no cenário organizacional fizeram com que se buscasse agilidade ao localizar um documento, além da redução do espaço destinado aos arquivos de aço nos escritórios. Nesse contexto, verifica-se que a aplicação da Tabela de Temporalidade Documental contribuiria como ferramenta norteadora para que a empresa implante sua Gestão Documental. Diante dessas mudanças, o profissional de secretariado vem ganhando destaque.

São as secretárias e secretários que, no universo corporativo, dão suporte às tomadas de decisão. São eles os responsáveis pela documentação da empresa e cabe ao profissional arquivar, localizar e manter em perfeita ordem os documentos, facilitando o acesso aos demais colaboradores da empresa ou departamento em que atua. A partir daí, a organização teria conhecimento dos

Revista de Gestão e Secretariado, São Paulo, v. 2, n. 1, p.56-76, jan./jun. 2011. 
documentos gerados, os que permanentemente teriam de ser guardados, os que poderiam ser digitalizados, e os papéis passíveis de serem eliminados.

O texto está organizado em seis tópicos, sendo o primeiro está constituído por essa introdução. Após, será descrita a metodologia utilizada na pesquisa. Nos tópicos três a cinco, apresentam-se o referencial teórico, as primeiras técnicas utilizadas, Gestão Documental e a relação da aplicação da Tabela de Temporalidade Documental com as normas ISO e o Gerenciamento Eletrônico de Documentos. O último tópico contempla as considerações finais.

\section{METODOLOGIA}

Do ponto de vista da sua natureza, o presente estudo pode ser classificado como uma pesquisa aplicada, visto que tem por objetivo gerar conhecimentos para aplicação prática, dirigidos à solução de problemas específicos.

Do ponto de vista de seus objetivos, de acordo com a abordagem de Gil, (1991), o estudo se caracteriza como uma pesquisa exploratória, pois visa proporcionar maior familiaridade com o problema com vistas a torná-lo explícito.

Considerando o ponto de vista dos procedimentos técnicos utilizados, tratase de uma pesquisa bibliográfica, visto que elaborada a partir de material já publicado, constituído principalmente de livros e artigos de periódicos.

\section{PRIMEIRAS TÉCNICAS}

O armazenamento de documentos, segundo Hora e Saturnino (2010, p. 3), "surgiu da necessidade que o homem tinha de registrar e difundir informações relacionadas ao seu tempo, a gerações futuras, organizando-as de acordo com as técnicas possíveis ou existentes em sua época". Os arquivos são conhecidos desde os tempos antigos. Há afirmativas de que surgiram na antiga Grécia e, naquele tempo, eram utilizados basicamente para depósito de documentos que garantiam direitos aos indivíduos ou instituições. Conforme Paes:

Revista de Gestão e Secretariado, São Paulo, v. 2, n. 1, p.56-76, jan./jun. 2011. 
As definições antigas acentuavam o aspecto legal dos arquivos como depósitos de documentos e papel de qualquer espécie, tendo sempre relação com os direitos das instituições ou indivíduos. Os documentos serviam apenas para estabelecer ou reivindicar direitos. (PAES, 2002, p. 19).

As organizações atuais estão envolvidas por um contexto dinâmico, no qual as mudanças ocorrem com muita rapidez. Segundo Castelo Branco (2008), essas mudanças impuseram às empresas uma corrida frenética por produtividade e competitividade, originando impactos nas formas tradicionais de gestão das organizações, inclusive exigindo novas posturas entre líderes e liderados. As informações são numerosas e a necessidade de comunicação eficaz e eficiente é premente.

Considerando-se estas necessidades, o cuidado com a documentação e a agilidade na localização das informações também crescem em importância, visto que as informações estratégicas só têm valor quando disponibilizadas no momento certo.

As informações devem ser disponibilizadas com dados claros e precisos que representem a realidade, porque são elementos fundamentais para subsidiar tomadas de decisão e propiciar o sucesso da instituição. Segundo Paes (2002, p. 21), "Para que os arquivos possam desempenhar suas funções, torna-se indispensável que os documentos estejam dispostos de forma a servir ao usuário com precisão e rapidez".

Atualmente, são objeto de arquivo os documentos que historiam a trajetória das instituições e/ou dos indivíduos. Solon Buck definiu "Arquivo" como: "[...] o conjunto de documentos oficialmente produzidos e recebidos por um governo, organização ou firma, no decorrer de suas atividades, arquivados e conservados por si e seus sucessores para efeitos futuros." (apud PAES, 2002, p. 19). Paes (2002), com base neste conceito, complementa que:

Arquivo é a designação genérica de um conjunto de documentos produzidos e recebidos por uma pessoa física ou jurídica, pública ou privada, caracterizado pela natureza orgânica de sua acumulação e conservado por essas pessoas ou por seus sucessores, para fins de prova ou informação. De acordo com a natureza do suporte, o arquivo terá a qualificação respectiva, como, por exemplo, arquivo audiovisual, fotográfico, iconográfico, de microformas, informático. (PAES, 2002, p. 24).

Revista de Gestão e Secretariado, São Paulo, v. 2, n. 1, p.56-76, jan./jun. 2011. 
De acordo com Paes (2002, p. 20), "a principal finalidade dos arquivos é servir à administração, constituindo-se, com o decorrer do tempo, em base do conhecimento da história" e "a função básica do arquivo é tornar disponível as informações contidas no acervo documental sob sua guarda".

A Associação de Arquivistas Brasileiros, citada por Freiberger (2007), adota a seguinte definição: "os arquivos representam um conjunto de documentos, produzidos ou recebidos e preservados por instituições públicas ou privadas, ou mesmo por pessoas físicas, em decorrência de seus negócios, de suas atividades específicas e no cumprimento de seus objetivos".

Assim, observa-se que o arquivo é formado pelo que pode ser útil no cumprimento de objetivos institucionais ou individuais, não sendo necessário, e nem viável, arquivar tudo o que se produz ou se recebe, tanto pelo acúmulo de papel com dados sem utilidade e sem forma de resgate, quanto pela necessidade de racionamento e uso inteligente de espaço.

Segundo Paes (2002), os arquivos são classificados em corrente, intermediário e permanente, onde arquivo corrente é formado de documentos vigentes, frequentemente consultados. Arquivo intermediário é formado de documentos vigentes que deixaram de ser usados frequentemente, mas podem ser requisitados por quem os produziu ou os recebeu. E arquivo permanente é formado pelos documentos que não têm valor nas tarefas administrativas, e sim, no contexto histórico e documental, para conhecimento do passado e da evolução da organização ou do indivíduo.

A tabela abaixo faz um comparativo das chamadas idades do documento em relação aos seus respectivos valores, suas médias de duração, tempo de manuseio e frequência de acesso, bem como seus locais de arquivamento:

Revista de Gestão e Secretariado, São Paulo, v. 2, n. 1, p.56-76, jan./jun. 2011. 


\begin{tabular}{|c|c|c|c|c|}
\hline $\begin{array}{l}\text { Idade do } \\
\text { documento }\end{array}$ & Valor & $\begin{array}{l}\text { Duração } \\
\text { Média }\end{array}$ & $\begin{array}{c}\text { Frequência de } \\
\text { uso/Acesso }\end{array}$ & $\begin{array}{c}\text { Local de } \\
\text { Arquivamento }\end{array}$ \\
\hline ADMINISTRATIVA & $\begin{array}{l}\text { Imediato ou } \\
\text { Primário }\end{array}$ & $\begin{array}{l}\text { Cerca de } 5 \\
\text { anos }\end{array}$ & $\begin{array}{l}\text {-documentos vigentes } \\
\text { - muito consultados } \\
\text {-acesso restrito ao } \\
\text { organismo produtor }\end{array}$ & $\begin{array}{l}\text { Arquivo } \\
\text { Corrente } \\
\text { (próximo ao } \\
\text { produtor) }\end{array}$ \\
\hline \multirow{3}{*}{ INTERMEDIÁRIA } & $\begin{array}{l}\text { I- Primário } \\
\text { reduzido }\end{array}$ & $\begin{array}{l}5+5=10 \\
\text { anos }\end{array}$ & $\begin{array}{l}\text { - documentos vigentes } \\
\text { - regularmente } \\
\text { consultados } \\
\text {-acesso restrito ao } \\
\text { organismo produtor }\end{array}$ & $\begin{array}{l}\text { Arquivo Central } \\
\text { (próximo à } \\
\text { administração) }\end{array}$ \\
\hline & $\begin{array}{l}\text { II- Primário } \\
\text { mínimo }\end{array}$ & $\begin{array}{l}10+20= \\
30 \text { anos }\end{array}$ & \multirow{2}{*}{$\begin{array}{l}\text { - documentos vigentes } \\
\text { - prazo precaucional } \\
\text { longo } \\
\text {-referência ocasional } \\
\text { - pouca frequência de } \\
\text { uso } \\
\text { - acesso público } \\
\text { mediante autorização }\end{array}$} & \multirow{2}{*}{$\begin{array}{l}\text { Arquivo } \\
\text { Intermediário } \\
\text { (exterior à } \\
\text { instituição ou } \\
\text { anexo ao } \\
\text { Arquivo } \\
\text { Permanente) }\end{array}$} \\
\hline & $\begin{array}{l}\text { III- } \\
\text { Secundário } \\
\text { Potencial }\end{array}$ & $\begin{array}{l}30+20= \\
50 \text { anos }\end{array}$ & & \\
\hline HISTÓRICA & $\begin{array}{l}\text { Secundário } \\
\text { Máximo }\end{array}$ & Definitiva & $\begin{array}{l}\text { - documentos que } \\
\text { perderam vigência } \\
\text { - valor permanente } \\
\text { - acesso público pleno }\end{array}$ & $\begin{array}{l}\text { Arquivo } \\
\text { Permanente ou } \\
\text { Histórico }\end{array}$ \\
\hline
\end{tabular}

Fonte: BERNARDES (1998).

Dudziak (2010, p. 8) considera que um dos aspectos essenciais a respeito da organização e gestão de documentos e arquivos é conhecer seus conceitos fundamentais. Finalizando o capítulo, citamos alguns termos e conceitos aplicáveis para a área secretarial e de relevância para a área da arquivística, segundo Paes (2002, p. 23-28):

$\checkmark$ ACERVO - Conjunto de documentos de um arquivo;

$\checkmark$ ADMINISTRAÇÃO DE ARQUIVO - Direção, supervisão e coordenação das atividades administrativas e técnicas de uma instituição ou órgão arquivístico;

$\checkmark$ ADMINISTRAÇÃO DE DOCUMENTO - Metodologia de programas para controlar a criação, o uso, a normalização, a manutenção, a guarda, a proteção e a destinação de documentos;

$\checkmark$ ARQUIVÍSTICA - Princípios e técnicas a serem observados na constituição,

Revista de Gestão e Secretariado, São Paulo, v. 2, n. 1, p.56-76, jan./jun. 2011. 
organização, desenvolvimento e utilização dos arquivos;

$\checkmark$ CORRESPONDÊNCIA - Comunicação escrita, recebida (passiva) ou expedida (ativa) apresentada sob várias formas (cartas, cartões postais, ofícios, memorandos, bilhetes, telegramas), podendo ser interna ou externa, oficial ou particular, ostensiva ou sigilosa;

$\checkmark$ DEPÓSITO - Ato pelo qual arquivos ou coleções são colocados, fisicamente, sob custódia de terceiros, sem que haja transferência da posse ou propriedade;

$\checkmark$ DOCUMENTO DE ARQUIVO - Aquele que produzido e/ou recebido por uma instituição pública ou privada, no exercício de suas atividades, constitua elemento de prova ou de informação;

$\checkmark$ DOCUMENTO OFICIAL - Aquele que, possuindo ou não valor legal, produz efeitos de ordem jurídica na comprovação de um fato;

$\checkmark$ DOCUMENTO PÚBLICO - Aquele produzido e recebido pelos órgãos do poder público, no desempenho de suas atividades;

$\checkmark$ DOCUMENTO SIGILOSO - Aquele que, pela natureza de seu conteúdo informativo, determina medidas especiais de proteção quanto a sua guarda e acesso ao público;

$\checkmark$ ELIMINAÇÃO - Destruição de documentos julgados destituídos de valor para guarda permanente;

$\checkmark$ GÊNERO DE DOCUMENTOS - Designação dos documentos segundo o aspecto de sua representação nos diferentes suportes: textuais, audiovisuais, iconográficos e cartográficos;

$\checkmark$ LISTA DE ELIMINAÇÃO - Relação de documentos específicos a serem eliminados, devidamente aprovada pela autoridade competente;

$\checkmark$ RECOLHIMENTO - Transferência de documentos dos arquivos 
intermediários para os permanentes;

$\checkmark$ TABELA DE TEMPORALIDADE - Instrumento de destinação, aprovado pela autoridade competente, que determina os prazos em que os documentos devem ser mantidos nos arquivos correntes e intermediários, ou recolhidos aos arquivos permanentes, estabelecendo critérios para microfilmagem e eliminação;

$\checkmark$ TRANSFERÊNCIA - Passagem dos documentos dos arquivos correntes para os intermediários.

A seguir, será abordado o conceito de arquivo e de documentos por outros autores, bem como o uso da Tabela de Temporalidade Documental na Gestão Documental.

\section{GESTÃO DOCUMENTAL: APLICAÇÃO DA TABELA DE TEMPORALIDADE DOCUMENTAL}

Os chamados "arquivos" na maioria das empresas e instituições são constituídos por arquivos de aço ou de madeira, com inúmeras pastas repletas de documentos em papel. Feijó (1988, p. 24) define que "documento são todos os papéis contendo informações que ajudem a tomar decisões, comuniquem decisões tomadas, registrem assuntos de interesse da organização ou do indivíduo".

Já para Avedon (2001), documento é um conjunto de informações em formato portátil, em formato papel, microfilme ou eletrônicos (magnético ou ópticos). Isso quer dizer que é possível a guarda de informações, de documentos em formato digital, em CDs, por exemplo.

$\mathrm{O}$ ato de arquivar significa guardar esses documentos de forma organizada, com o objetivo de ser consultado quando necessário. Conforme Sabino e Rocha (2004), o tempo para que esses documentos permaneçam arquivados é definido por lei e/ou norma interna, dependendo da utilização e importância do documento.

Revista de Gestão e Secretariado, São Paulo, v. 2, n. 1, p.56-76, jan./jun. 2011. 
Assim como os tipos de arquivamento podem variar, os documentos a serem arquivados também podem ser de diferentes gêneros. Além dos escritos ou textuais, mais conhecidos e utilizados, os documentos podem aparecer em formatos eletrônicos e de tantas outras maneiras, como é o caso dos iconográficos (fotografias, desenhos, gravuras), sonoros (CDs e fitas K7) ou ainda cartográficos (mapas e plantas).

O arquivamento somente é eficaz quando o método de arquivamento e sua disposição são conhecidos pelos demais colegas de setor ou da própria empresa, exige do profissional incumbido dessa responsabilidade, secretário executivo ou arquivista, constante atualização, compromisso ético de trabalho para prestação de um serviço de qualidade.

Segundo Dudziak (2010), o profissional de secretariado executivo deve manter-se sempre atualizado, antecipando-se às necessidades que possam surgir. A autora (2010, p. 19) justifica, ainda, que, a gestão de documentos e arquivos é uma atividade que requer conhecimentos, habilidades e atitudes especiais, podendo demandar a realização de estudos específicos, bem como cursos de capacitação e atualização.

Num contexto empresarial em que a informação e o conhecimento adquiriram grande valor estratégico, a Gestão Documental ganhou ênfase. Nas mãos do profissional de Secretariado, o arquivamento passou de tarefa comum a mecanismo de guarda das principais informações da empresa, que não podem ser extraviadas, tampouco danificadas. Sabino e Rocha (2004, p. 85) definem que "os documentos constituem provas, e devem ser tratados como um patrimônio da empresa, pois ele poderá, oportunamente, definir questões vitais da organização, ou ainda salvá-la de prejuízos, devido a não comprovação de documentos legais ou fiscais".

Segundo Nazário (2008), Gestão Documental é todo processo relacionado ao recebimento, guarda, tramitação e recuperação dos documentos que suportam as atividades operacionais, finais e estratégicas de uma Empresa, área ou departamento, devendo ser executado de maneira ágil e integrada.

Revista de Gestão e Secretariado, São Paulo, v. 2, n. 1, p.56-76, jan./jun. 2011. 
Segundo os autores Baldam, Valle e Cavalcanti (2002, p.35), fazem parte do ciclo de vida dos documentos as etapas ilustradas abaixo: criação; publicação e distribuição; uso ativo; pós-decisão; arquivo; e descarte.

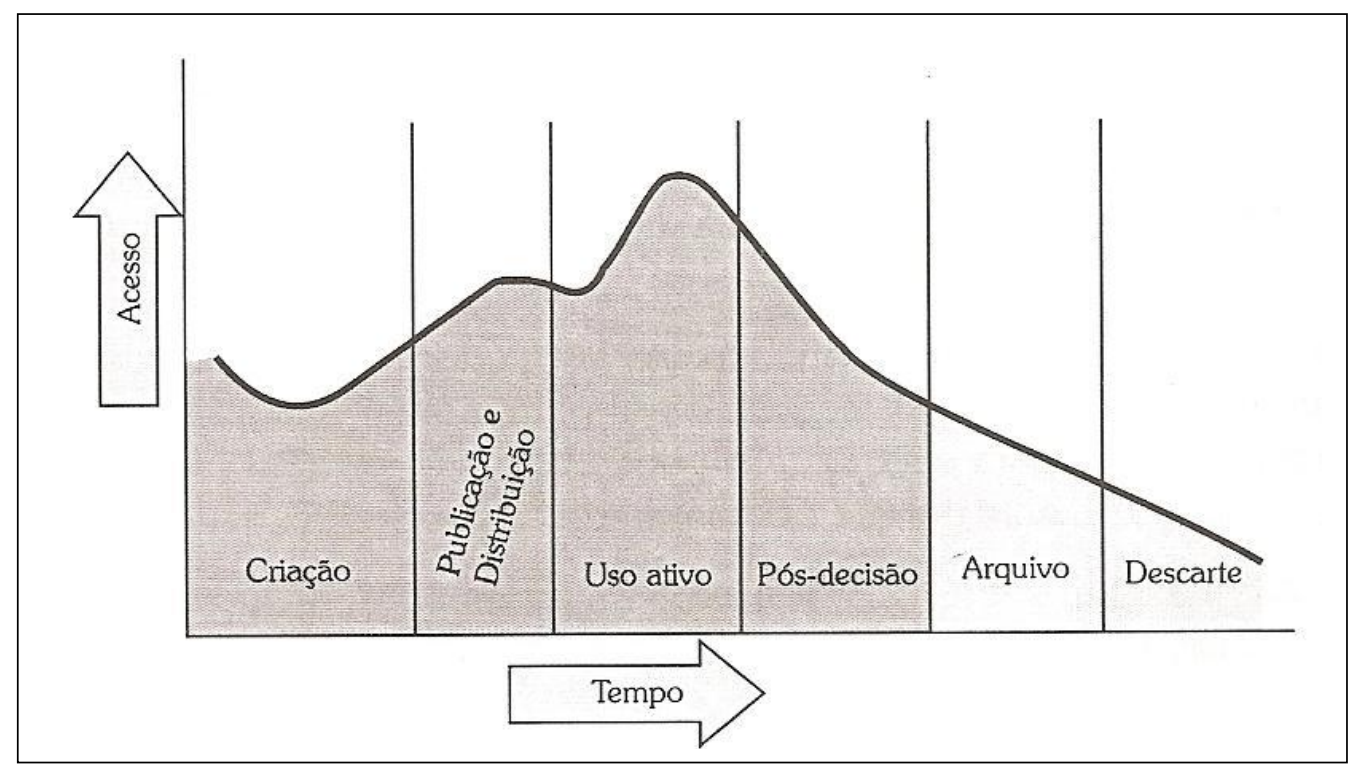

Fonte: BALDAM, VALLE \& CAVALCANTI (2002, p. 35).

A figura acima indica que nas três primeiras etapas, da criação ao uso-ativo do documento, a frequência de consultas e acesso é mais intensa. Já nas duas últimas etapas, arquivo e descarte, a utilização dos documentos diminui. Nestas etapas, a preocupação com o destino dos documentos e o tempo que eles deverão permanecer arquivados devem ser considerados.

Para acompanhar a vida dos atestados e ofícios emitidos é necessária a elaboração de uma tabela de temporalidade documental (TTD). Paula (1995) considera a tabela um instrumento norteador desse acompanhamento. Segundo o Arquivo Nacional (2001):

A tabela de temporalidade é um instrumento arquivístico resultante de avaliação, que tem por objetivos definir prazos de guarda e destinação de documentos, com vista a garantir o acesso à informação a quantos dela necessitem. Sua estrutura básica deve necessariamente contemplar os conjuntos documentais produzidos e recebidos por uma instituição no exercício de suas atividades, os prazos de guarda nas fases corrente e intermediária, a destinação final - eliminação ou guarda permanente -, além de um campo para observações necessárias à sua compreensão e aplicação. 
Já Sabino e Rocha (2004) complementam que a tabela é o esquema do ciclo de vida documental da organização, elaborado após a análise da documentação. Por meio dessa tabela empresas e órgãos definem o que deve permanecer e o que deve ser descartado. As contribuições estão na agilidade em recuperar documentos e na eficácia sobre a gestão documental.

Paula (1995) relaciona mais benefícios, tais como: racionalização de espaço físico; velocidade de respostas às questões formuladas ao sistema; padronização e adequação de materiais arquivísticos; menor envolvimento de homem/hora na atividade de processamento de informações; melhoramento do processo de tomada de decisões em todos os níveis organizacionais; contribuição à excelência pessoal considerando a satisfação do cliente; e, preservação da memória técnico-administrativa.

Ao elaborar uma TTD, deve-se verificar os documentos/formulários que circulam no setor ou empresa. Sabino e Rocha (2004) destacam que a tabela deve ser de conhecimento de todos os setores envolvidos, e aprovados pela alta administração.

Os itens a serem contemplados são, na maioria dos exemplos pesquisados: competências, atividades, documentos gerados, tempo de arquivamento, destino e índice de recuperação. Sabino e Rocha (2004) complementam que:

Os dados básicos a serem incluídos em uma tabela são: nome do órgão e da atividade administrativa, espécie e assunto do documento, existência de vias e/ou reproduções em outros setores, prazos de guarda nos arquivos corrente e intermediários, destinação (p. 87).

As primeiras tabelas contemplavam itens como competências, que seriam os objetivos de determinadas atividades ou documentos gerados (planejar, coletar, controlar...). Hoje, com a gestão por processos de negócio, a tendência está sendo listar os processos da empresa ou setor, identificando as atividades neles relacionados e os documentos gerados.

Ao implantar a TTD, devem ser considerados os conceitos de tipos de arquivo, ou seja, saber que os documentos que serão consultados com mais frequência serão armazenados no Arquivo Corrente ou Ativo. Há também o Intermediário, onde são arquivados os documentos de consulta mediana. Já no

Revista de Gestão e Secretariado, São Paulo, v. 2, n. 1, p.56-76, jan./jun. 2011. 
Arquivo Inativo ou Permanente serão armazenados os documentos cuja frequência de busca é eventual, mas de valor fiscal, legal, técnico e/ou histórico.

A consequência da não utilização dessa Gestão Documental implicará a reorganização frequente do acervo documental, conforme explica Paula (1995, p. 31):

A organização de uma massa documental que não esteja norteada por uma Tabela de Temporalidade, em pouquíssimo tempo necessitará novamente de uma reorganização, pois não se definindo por quanto tempo manter ou quando e o que deve ser expurgado, este acervo crescerá desordenadamente e estará de novo, em breve, precisando de nova triagem. O mais grave, é que se terá que retrabalhá-lo por inteiro, pois não há como separar o "joio do trigo" sem que se passe pasta por pasta. (PAULA, 1995, p. 31).

Em seguida serão abordadas as contribuições da Gestão Documental para a implantação das normas ISOs e o Gerenciamento Eletrônico de Documentos.

\section{ISOS E GERENCIAMENTO ELETRÔNICO DE DOCUMENTOS: RESULTADOS DA GESTÃO DOCUMENTAL}

A nova realidade do mundo empresarial são os Sistemas Integrados de Gestão, que contemplam itens como qualidade, meio ambiente, saúde e segurança. Segundo os autores Baldam, Valle e Cavalcanti (2002), a documentação, que é de extrema relevância para a certificação por normas ISO e por outras, terá de ser controlada e descrita nos manuais de gestão, assegurando:

- que haja um registro sistemático de procedimentos, de decisões e de eventos;

- que nenhum documento esteja disponível para consulta, sem antes ter sido analisado e aprovado pelas pessoas autorizadas para isto;

- que os documentos possam ser rápida e corretamente localizados;

- que os documentos sejam periodicamente analisados e, quando necessário, revisados, com aprovação de pessoas autorizadas para isto;

- que todos os locais de trabalho possam dispor das versões atualizadas dos documentos que Ihes sejam pertinentes;

Revista de Gestão e Secretariado, São Paulo, v. 2, n. 1, p.56-76, jan./jun. 2011. 
- que todos os documentos obsoletos sejam removidos não só dos seus locais de origem, mas também dos locais de uso;

- que os documentos relacionados a exigências legais ou à memória técnica identificados e conservados. (BALDAM, VALLE \& CAVALCANTI, 2002, p. 23).

Há uma evidente relação da aplicação da Gestão Documental e uso da TTD, com a gestão da qualidade total e a implantação dos ISOs. Conforme Maranhão (2002), as maneiras de arquivar os documentos variam com o passar do tempo e das pessoas que lidam com estes:

Por mais perfeitas que sejam as práticas, elas se degradam com o tempo, além de serem voláteis. Por quê? Porque as práticas estão organizadas na memória das pessoas, que podem mudar de empresa, de humor ou de objetivos, podem faltar ao trabalho, adoecer ou morrer. Há necessidade, portanto, de consolidar as práticas, mediante documentação normativa (normas ou padrões de trabalho). Tais documentos formam a base documentada da organização. A base documentada forma 0 alicerce de conhecimento explícito da organização uma vez que o conhecimento implícito está na cabeça das pessoas e não é necessariamente difundido ou aproveitado para agregação de valor. (MARANHÃO, 2002, p.18).

Já Paula (1995) explica que o requisito Documentação da ISO 9000, Qualidade Total, instrui sobre a necessidade de se definir o tempo de guarda e local de arquivamento dos documentos, garantindo decisões tomadas com mais precisão, devido às informações estar atualizadas e em perfeita ordem.

Com a aplicação da TTD, é possível documentar o tempo de guarda dos documentos, quais foram digitalizados e guardados em formato físico, bem como padronizar a maneira de arquivamento, não importando quem está ou estará neste cargo no setor ou empresa.

A tecnologia da informação (TI), através do Gerenciamento Eletrônico de Documentos (GED), traz inúmeros recursos para esse fim. Para Albertin e Albertin (2005) "a tecnologia da Informação (TI) tem sido considerada como um dos componentes mais importantes do ambiente empresarial atual, sendo que as organizações brasileiras têm utilizado ampla e intensamente esta tecnologia tanto em nível estratégico como operacional".

O GED, Gerenciamento Eletrônico de Documentos, segundo Koch (1998), é o somatório de todas as tecnologias e produtos que visam gerenciar informações 
de forma eletrônica. É através desse sistema que é possível disponibilizar o documento, informação, a vários setores na empresa auxiliando na tomada de decisão.

Guimarães (2005) comenta que "a qualidade das decisões na empresa está ligada aos dados disponíveis, à sua facilidade de comunicá-los a qualquer momento". Guimarães (2005) também destaca que o método tradicional de processamento da informação está sendo substituído pelo automatizado. Isso significa que o processo tradicional, que corresponde à guarda de documentos em arquivos físicos, está passando gradativamente a automatizado. Com este processo, o arquivo físico passa a ser um sistema de gerenciamento de dados multiusuário.

\begin{abstract}
O Gerenciamento Eletrônico de Documentos (GED) é uma técnica, um sistema, uma metodologia para 0 tratamento $e \quad 0$ processamento automatizado de documentos em papel e/ou suas cópias em microfilme. (AVEDON, 2002, p. 3)

O Gerenciamento Eletrônico de Documentos (GED) é uma configuração de equipamentos, software e, normalmente, de recursos de telecomunicações baseada em computador e automatizada que armazena e gerencia imagens de documentos e seus índices codificados - que podem ser lidas por máquinas e processadas por computador para recuperação sob solicitação. (AVEDON, 2002, p. 11).
\end{abstract}

As vantagens de um Gerenciamento Eletrônico de Documentos, do ponto de vista organizacional, segundo Avedon (2002), são: quantidade de usuários que terão acesso à informação, auxílio à tomada de decisão; número de estações de trabalho automatizadas; produtividade e redução de funcionários adicionais; tempo de acesso à documentação; melhor atendimento aos clientes, respostas e dados consultados em menor tempo; além de redução de espaço físico e documentos/arquivos perdidos.

Finalizando, Baldam, Valle e Cavalcanti (2002) relatam as vantagens do GED sob quatro aspectos.

1) Para o usuário e o cliente: redução do tempo de processamento e manuseio do papel; aumento de satisfação do usuário; incremento à produtividade; melhoria da satisfação com o trabalho; acesso imediato e 
multiusuário a qualquer informação; melhoria da qualidade do trabalho; alta velocidade e precisão na localização de documentos; e, melhor atendimento ao cliente por proporcionar respostas mais precisas e instantâneas.

2) Para a gestão documental: melhor controle dos documentos; redução do espaço físico de armazenagem; facilidade de implementar temporalidade documental; e, minimização de perda e extravio de documentos.

3) Para o pessoal de TI (Tecnologia da Informação): integração com outros sistemas e tecnologias; facilidade adicional para implantar empresa virtual; disponibilidade instantânea de documentos sem limites físicos; gerenciamento e otimização do workflow; possibilidade da empresa virtual sem limites físicos; maior agilidade nas transações entre empresas; e maior velocidade na implementação de mudanças nos processos.

4) Para a redução e proteção de investimentos: redução de custos com novos escritórios/depósitos/equipamentos; proteção do patrimônio; eliminação de retornos; proteção contra processos; eliminação de fraudes, principalmente em agências governamentais; e proteção contra catástrofes que poderiam danificar seu acervo.

Segundo estudo publicado na Imaging Magazine citada por Koch (1998), a civilização moderna produziu nos últimos cinquenta anos, a mesma quantidade de papel produzida nos últimos cinco mil anos anteriores e esse número tende a aumentar, fato que justifica a importância da digitalização de documentos.

Revista de Gestão e Secretariado, São Paulo, v. 2, n. 1, p.56-76, jan./jun. 2011. 


\section{CONSIDERAÇÕES FINAIS}

Ao realizar um trabalho de arquivística, é necessária uma avaliação do que já foi feito em termos de organização até aquele momento. Paes (2002) sugere uma metodologia específica. Seria adequado um levantamento e análise de dados existentes, planejamento, seguido da implantação, manutenção e acompanhamento.

A revisão do fluxo documental é de extrema importância. A partir dessa etapa é possível analisar se os arquivos são compostos de documentos originados das atividades que o setor executa, oriundos de seus processos, ou se, por exemplo, os documentos são arquivados com valor histórico.

A partir daí, é possível analisar se o trabalho requer a implantação desde as primeiras técnicas, se é o caso da aplicação a partir da Tabela de Temporalidade Documental, ou se já praticada, desenvolver o Gerenciamento Eletrônico de Documentos, visando à Qualidade Total dos serviços prestados.

A partir da aprovação de uma Tabela de Temporalidade Documental será possível descartar parte significativa de documentos acumulados em qualquer setor. O processo de arquivamento, principalmente no acervo permanente, poderá ser controlado, guardando-se apenas o que é solicitado na tabela e os documentos que servirão para futuras pesquisas. A informação poderá ser buscada com mais agilidade e praticidade e o espaço físico do escritório não sofrerá com acúmulo de papel.

Na nova realidade do mundo empresarial, um arquivo bem organizado e com técnica adequada, além da definição do destino dos documentos compõem os Sistemas Integrados de Gestão, contemplando itens como qualidade, meio ambiente, saúde e segurança.

Revista de Gestão e Secretariado, São Paulo, v. 2, n. 1, p.56-76, jan./jun. 2011. 


\section{REFERÊNCIAS}

ALBERTIN, Alberto Luiz \& ALBERTIN, Rosa Maria de Moura (Org.). Tecnologia de informação: desafios da tecnologia de informação aplicada aos negócios. São Paulo: Atlas, 2005. 207 p. ISBN 85-224-4145-6.

ARQUIVO NACIONAL (BRASIL). Conselho Nacional de Arquivos, Classificação, temporalidade e destinação de documentos de arquivo; relativos às atividadesmeio da administração pública/Arquivo Nacional. Rio de Janeiro: Arquivo Nacional, $2001 . \quad$ Disponível em: http://www.conarq.arquivonacional.gov.br/media/publicacoes/cdigo_de_classific acao.pdf. Acesso em: 18 out. 2010.

AVEDON, Don M. Tecnologia de documentos: definições e descrições. São Paulo: Cenadem, 2001.

. GED de $A$ a $Z$ : tudo sobre gerenciamento eletrônico de documentos. São Paulo: Cenadem, 2002.

BALDAM, Roquemar de Lima; VALLE, Rogerio \& CAVALCANTI, Marcos. GED: gerenciamento eletrônico de documentos. São Paulo: Érica, 2002.

BERNARDES, Ieda Pimenta. Como avaliar documentos de arquivo. São Paulo: Arquivo do Estado, 1998. Disponível em: <http://www.saesp.sp.gov.br/cf1.pdf> Acesso em: 10 jun. 2007.

CASTELO BRANCO, Valdec Romero. Aprendizagem organizacional, gestão do conhecimento e universidade corporativa: instrumentos de um mesmo construto. Disponível em: http://www.administradores.com.br/informe-se/producaoacademica/aprendizagem-organizacional-gestao-do-conhecimento-euniversidade-corporativa-instrumentos-de-um-mesmo-construto/3236/. Acesso em: 5 abr. 2011.

Revista de Gestão e Secretariado, São Paulo, v. 2, n. 1, p.56-76, jan./jun. 2011. 
DUDZIAK, Elisabeth Adriana. Arquivos e documentos empresariais: da organização cotidiana à gestão eficiente. In: Revista de Gestão e Secretariado, v. 1, n. 1. São Paulo, 2010.

FEIJÓ, Virgílio de Mello. Documentação e arquivos. Porto Alegre: Sagra, 1988.

FREIBERGER, Zélia. Gestão de Documentos e Arquivística. 2007. Disponível em: http://www.diaadia.pr.gov.br/det/arquivos/File/e-TEC/APOSTILAS/Vol2-GP/MECGestao.pdf. Acesso em: 21 out. 2010.

GIL, Antonio Carlos. Como elaborar projetos de pesquisa. São Paulo: Atlas, 1991. GUIMARÃES, Márcio Eustáquio. O livro azul da secretária moderna. 22. ed. São Paulo: Érica, 2005.

HORA, Sérgio Ricardo Almeida da; SATURNINO, Luyz Paullo Targino \& SANTOS, Eliete Correia dos. A evolução do arquivo e da arquivologia na perspectiva da história. Disponível em: http://www.webartigos.com/articles/33326/1/AEVOLUCAO-DO-ARQUIVO-E-DA-ARQUIVOLOGIA-NA-PERSPECTIVA-DAHISTORIA/pagina1.html\#ixzz1AkkYadgr. Acesso em: 11 jan. 2011.

$\mathrm{KOCH}$, Walter W. Gerenciamento eletrônico de documentos: conceitos, tecnologias e considerações gerais. São Paulo: Cenadem, 1998.

MARANHÃO, Mauriti. ISO série 9000: manual de implementação: versão 2000. 6 . ed. Rio de Janeiro: Qualitymark, 2002.

NAZÁRIO, Claudiane. Gestão de Documentos - Metodologia Documentar. Publicado em 29/09/2008. Disponível em $<$ http://www.documentar.com.br/pt/pdf/metodologia_gdi.pdf>. Acesso em: 12 abr. 2009.

PAES, Marilena Leite. Arquivo: teoria e prática. $3^{a}$ ed. rev. ampl. Reimpr. - Rio de Janeiro: FGV, 2002.

Revista de Gestão e Secretariado, São Paulo, v. 2, n. 1, p.56-76, jan./jun. 2011. 
PAULA, Rosália Paraíso Matta de. Como elaborar a tabela de temporalidade documental: racionalização de custos de armazenagem e administração de arquivos empresariais. São Paulo: Cenadem, 1995.

SABINO, Rosimeri Ferraz \& ROCHA, Fabio Gomes. Secretariado: do escriba ao web writer. Rio de Janeiro: Brasport, 2004.

Revista de Gestão e Secretariado, São Paulo, v. 2, n. 1, p.56-76, jan./jun. 2011. 